\title{
Exhaust Emissions and Physicochemical Properties of Hydrotreated Used Cooking Oils in Blends with Diesel Fuel
}

\author{
Iraklis Zahos-Siagos $(\mathbb{D}$ and Dimitrios Karonis $(\mathbb{D}$ \\ Laboratory of Fuels Technology and Lubricants, School of Chemical Engineering, National Technical University of Athens, \\ 9 Iroon Polytechniou, Zografou Campus, 15780 Zografou, Greece \\ Correspondence should be addressed to Dimitrios Karonis; dkaronis@central.ntua.gr
}

Received 22 February 2018; Accepted 27 June 2018; Published 1 August 2018

Academic Editor: Michael Harris

Copyright (c) 2018 Iraklis Zahos-Siagos and Dimitrios Karonis. This is an open access article distributed under the Creative Commons Attribution License, which permits unrestricted use, distribution, and reproduction in any medium, provided the original work is properly cited.

\begin{abstract}
Hydroprocessing of liquid biomass is a promising technology for the production of "second generation" renewable fuels to be used in transportation. Its products, normal paraffins, can be further hydrotreated for isomerization in order to improve their cold flow properties. The final product, usually referred to as "paraffinic diesel," is a high cetane number, clean burning biofuel which is rapidly gaining popularity among researchers and the industry. Nevertheless, the costly isomerization step can be omitted if normal paraffins are to be directly mixed with conventional diesel in low concentrations. In this work, nonisomerized paraffinic diesel produced through hydrotreating of used cooking oil (hydrotreated used cooking oil (HUCO)) has been used in 4 blends (up to $40 \% \mathrm{v} / \mathrm{v}$ ) with conventional diesel fuel. The blends' properties have been assessed comparatively to European EN 590 and EN 15940 standards (concerning conventional automotive diesel fuels and paraffinic diesel fuels from synthesis or hydrotreatment, resp.). Furthermore, the HUCO blends have been used in a standard stationary diesel engine-generator set. The blends have been considered as "drop-in replacements" for standard diesel fuel. As such, no engine modifications took place whatsoever. The engine performance and exhaust emissions of steady-state operation have been examined in comparison with engine operation with the baseline conventional diesel fuel.
\end{abstract}

\section{Introduction}

Compression ignition engines (i.e., diesel engines) have been undoubtedly the dominant powertrain in transportation sector's medium- to heavy-duty applications (trucks, buses, and marine propulsion) for decades now. Moreover, during the previous years, diesel engine's share in the passenger vehicle market has been increasing [1]. However, recently, diesel engines are being more and more criticized for their exhaust emissions, mainly nitrogen oxides $\left(\mathrm{NO}_{x}\right)$ and particulate matter (PM) as well as their share of carbon dioxide $\left(\mathrm{CO}_{2}\right)$ emission to the atmosphere $[2,3]$.

In an effort to reduce internal combustion engines' $\mathrm{CO}_{2}$ footprint as well as to mitigate their harmful exhaust emissions, fuel related technologies have been intensively studied and implemented to produce alternative fuels of renewable origin as blending components with conventional fossil fuels, since the 1980s. In the transportation sector, these first generation biofuels are still employed to both obsolete and contemporary compression ignition engines worldwide.

The most widely used renewable substitute for conventional diesel is the product of transesterification of fatty acid triglycerides. This technology, dating back to mid-19th century $[4,5]$, has been widely used since the 1990 s to produce fatty acid methyl esters (FAME) as a renewable blending component for diesel fuel. This so-called biodiesel has been extensively studied and successfully used in compression ignition engines over the last few decades $[5,6]$. However, disadvantages such as the competition over the land used for both food and energy crops as well as technical disadvantages such as microbial contamination and storage stability led to the development of second-generation biofuels [7-13].

The main goal of such second-generation biofuel technologies is to extend biofuel production capacity by 
incorporating the residual biomass (usually nonedible parts of food crops, industrial organic waste, slaughterhouse waste, used cooking oils, etc.) to create high-quality, clean burning paraffins and isoparaffins within naphtha, kerosene, and diesel ranges that can be directly used in the transportation sector powertrains.

Catalytic hydroprocessing has been a well-established process in the petrochemical industry for over a century, and it has also been examined for conversion of vegetable oils since the early 1990s [7, 14]. It can be employed for various purposes such as heteroatom (sulfur, nitrogen, oxygen, and metals) removal, saturation of olefins and aromatics, isomerization, and cracking. The technology of various catalytic hydroprocessing implementations is closely intertwined with the catalytic materials that are being developed [15]. As a result, research and development of hydroprocessing catalysts has ultimately enabled the conversion of heavier and lower quality biomass feedstocks [7, 16-19].

The resulting products of catalytic hydroprocessing can be fuels derived from the waste biomass (thus increasing sustainability of biofuels without competing with food crops cultivation) with significantly improved properties as compared to first-generation biofuels and fossil fuels (high heating value, high cetane number, increased oxidation stability, negligible acidity, increased saturation level, negligible aromatic content, and low sulfur content) [7, 20-22].

The conversion of natural triglycerides into hydrocarbons in a hydroprocessing setting of liquid biomass takes place through the basic processes of cracking, saturation, heteroatom removal, and isomerization (Figure 1).

(i) Cracking converts large molecules into smaller ones and, in boiling range of conventional naphtha, kerosene and diesel ranges.

(ii) Saturation mainly converts $\mathrm{C}=\mathrm{C}$ (double) bonds of liquid biomass into $\mathrm{C}-\mathrm{C}$ (single) bonds. Formation of naphthenes can take place too, through saturation of various unsaturated cyclic compounds and aromatic compounds.

(iii) Heteroatoms such as sulfur (S) and nitrogen $(\mathrm{N})$ are being removed through standard mechanisms in the form of $\mathrm{H}_{2} \mathrm{~S}$ and $\mathrm{NH}_{3}$. Oxygen (O) removal takes place through deoxygenation, decarbonylation, and decarboxylation. Oxygen presence causes many disadvantages that characterize first-generation biodiesel (i.e., fatty acid alkyl esters) because it decreases oxidation stability, increases acidity and corrosivity, reduces the heating value, and indirectly promotes the microbial growth due to presence of water. Therefore, oxygen removal is of utmost importance during liquid biomass hydroprocessing.

(iv) The straight chain paraffins deriving from the above reactions, generally exhibit excellent physicochemical properties as mentioned before, but they also suffer from poor cold flow properties. Isomerization can transform normal paraffins into isoparaffins, thus greatly improving cold flow properties.
The isomerization normally takes place in a second reactor, as it requires a different catalyst to promote isomerization reactions [7]. This step, however, adds an extra cost to overall biofuel production not to mention that there are cases where it may not be needed (e.g., when paraffinic diesel is to be mixed in relatively small proportions with conventional diesel, resulting in negligible deterioration of final blend's cold flow properties). Another use for nonisomerized paraffinic diesel could be the upgrade of lowquality gasoil fuels through strategic blending [14, 23]. Some other researchers propose the route of coprocessing of liquid biomass mixed with gas oil stream in refinery operating infrastructures $[16,22-26]$ in order to keep the production costs of isomerized paraffinic diesel low, although this requires a consistent flow of biomass feedstock to cope with refineries' large processing capacities.

In the present work, nonisomerized paraffinic diesel derived from hydrotreatment of the municipal waste liquid biomass, namely, used cooking oils (hydrotreated used cooking oil (HUCO)), was mixed in 10, 20, 30, and 40 percent by volume with conventional, additive-free ultralow sulfur diesel (ULSD). Initially, the physicochemical properties of the blends were measured and evaluated comparatively to EN 590 for standard automotive diesel fuels and EN 15940 for paraffinic diesel fuels from synthesis or hydrotreatment. The 4 blends were also evaluated in a standard stationary diesel engine with regard to their effect on engine operation and exhaust emissions, compared to baseline ULSD fuel.

\section{Fuels}

The baseline diesel fuel was supplied by Hellenic Petroleum SA. This is a high-quality diesel fuel coming from the hydrocracking unit of the refinery and was free of any additives whatsoever. Measured properties of the baseline ULSD are presented in Table 1.

HUCO was supplied by the Centre for Research and Technology Hellas (CERTH). The catalytic hydrotreatment technology used for production of this fuel was developed and demonstrated in the hydrotreating pilot plants of the Chemical Processes and Energy Resources Institute of CERTH, via the financial contribution of the BIOFUELS-2G LIFE+ project [27]. A total of 2 tons of fuel was produced from used cooking oil collected from local restaurants. Table 2 shows the composition of this nonisomerized paraffinic diesel fuel [28]. The high concentration of normal paraffins in the HUCO explains the excellent ignition quality characteristics of the fuel, as well as its poor cold flow properties.

The blending of the two fuels took place under warm ambient conditions (during summer) in order for HUCO to be in fully liquid state. HUCO was mixed in 10, 20, 30, and 40 percent by volume with the baseline ULSD fuel. The two fuels demonstrated excellent mixing compatibility with each other; therefore, the 4 samples created (hereinafter referred to as $\mathrm{H} 10, \mathrm{H} 20, \mathrm{H} 30$, and $\mathrm{H} 40$ ) were perfectly homogenous during storage and utilization. The measured properties of the 4 blends are presented in Table 1. 


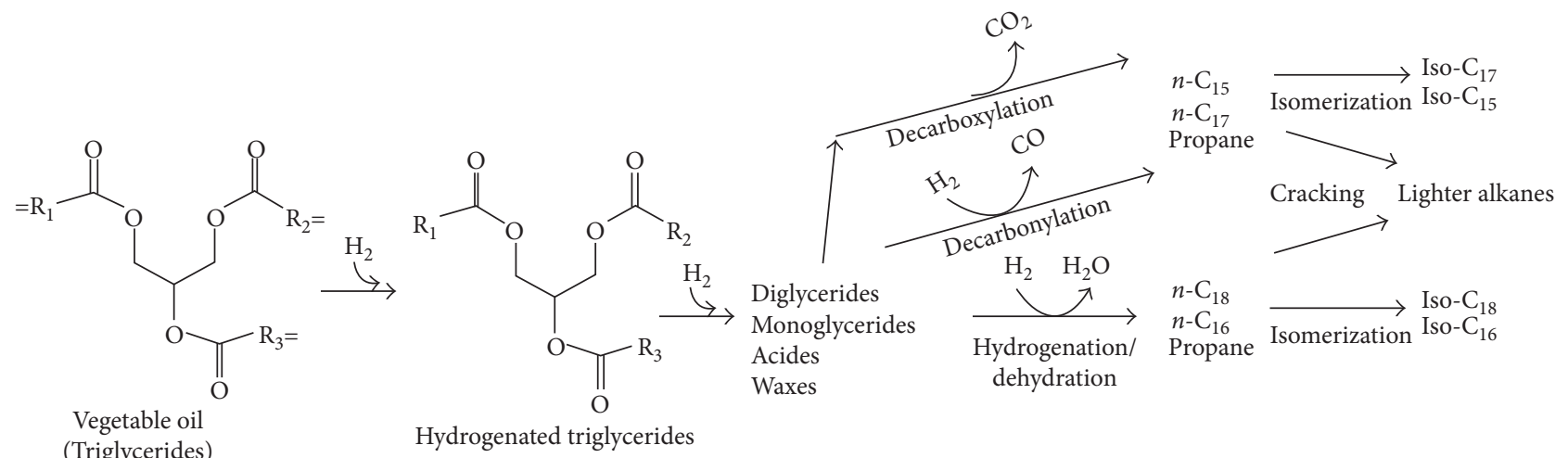

FIgURE 1: Reaction pathway for conversion of triglycerides to alkanes [22].

TABle 1: Measured properties of the baseline ULSD and HUCO fuels.

\begin{tabular}{|c|c|c|c|c|c|c|c|c|c|c|c|c|}
\hline \multirow[t]{2}{*}{ Property } & \multirow[t]{2}{*}{ ULSD } & \multirow[t]{2}{*}{ HUCO } & \multirow[t]{2}{*}{$\mathrm{H} 10$} & \multirow[t]{2}{*}{$\mathrm{H} 20$} & \multirow[t]{2}{*}{$\mathrm{H} 30$} & \multirow[t]{2}{*}{$\mathrm{H} 40$} & \multirow[t]{2}{*}{ Unit } & \multicolumn{2}{|c|}{ EN 590 limits } & \multicolumn{2}{|c|}{$\begin{array}{c}\text { EN } 15940 \text { limits } \\
\text { (class A) }\end{array}$} & \multirow{2}{*}{$\begin{array}{l}\text { Measurement } \\
\text { method }\end{array}$} \\
\hline & & & & & & & & Minimum & Maximum & Minimum & Maximum & \\
\hline Density $\left(15^{\circ} \mathrm{C}\right)$ & 830.8 & 790.8 & 825.9 & 821.8 & 817.6 & 813.2 & $\mathrm{~kg} / \mathrm{m}^{3}$ & 820.0 & 845.0 & 765.0 & 800.0 & EN ISO 12185 \\
\hline Viscosity $\left(40^{\circ} \mathrm{C}\right)$ & 4.255 & 3.780 & 4.166 & 4.111 & 4.081 & 4.033 & $\mathrm{~mm}^{2} / \mathrm{s}$ & 2.00 & 4.50 & 2.00 & 4.50 & ASTM D7042 \\
\hline $\mathrm{IBP}^{\mathrm{a}}$ & 182 & 255 & 182 & 183 & 184 & 185 & ${ }^{\circ} \mathrm{C}$ & & & & & EN ISO 3405 \\
\hline $\mathrm{T} 10^{\mathrm{b}}$ & 255 & 292 & 260 & 263 & 267 & 271 & ${ }^{\circ} \mathrm{C}$ & & & & & EN ISO 3405 \\
\hline $\mathrm{T} 50^{\mathrm{b}}$ & 297 & 298 & 298 & 299 & 299 & 300 & ${ }^{\circ} \mathrm{C}$ & & & & & EN ISO 3405 \\
\hline $\mathrm{T} 90^{\mathrm{b}}$ & 351 & 311 & 351 & 349 & 346 & 343 & ${ }^{\circ} \mathrm{C}$ & & & & & EN ISO 3405 \\
\hline T95 ${ }^{\mathrm{b}}$ & 361 & 322 & 361 & 360 & 358 & 358 & ${ }^{\circ} \mathrm{C}$ & & 360 & & 360 & EN ISO 3405 \\
\hline $\mathrm{FBP}^{\mathrm{c}}$ & 373 & 349 & 373 & 371 & 370 & 368 & ${ }^{\circ} \mathrm{C}$ & & & & & EN ISO 3405 \\
\hline $\mathrm{DCN}^{\mathrm{d}}$ & 60.3 & 102.7 & 63.1 & 65.5 & 68.1 & 72.1 & & 51.0 & & 70.0 & & ASTM D7170 \\
\hline $\mathrm{CCI}^{\mathrm{e}}$ & 65.2 & 95.6 & 67.9 & 70.7 & 73.6 & 77.1 & & 46.0 & & & & EN ISO 4264 \\
\hline $\mathrm{CFPP}^{\mathrm{f}}$ & -8 & 21 & -8 & -7 & -1 & 4 & ${ }^{\circ} \mathrm{C}$ & & -5 & & -5 & EN 116 \\
\hline Sulfur content & 1.0 & 2.6 & 1.2 & 1.3 & 1.5 & 1.6 & $\mathrm{mg} / \mathrm{kg}$ & & 10.0 & & & EN ISO 20846 \\
\hline $\begin{array}{l}\text { Monoaromatic } \\
\text { content }\end{array}$ & 7.42 & 0.60 & 6.74 & 6.06 & 5.37 & 4.69 & $\% \mathrm{w} / \mathrm{w}$ & & & & & EN 12916 \\
\hline $\begin{array}{l}\text { Diaromatic } \\
\text { content }\end{array}$ & 0.47 & 0.00 & 0.42 & 0.38 & 0.33 & 0.28 & $\% \mathrm{w} / \mathrm{w}$ & & & & & EN 12916 \\
\hline $\begin{array}{l}\text { Tri+ aromatic } \\
\text { content }\end{array}$ & 0.03 & 0.00 & 0.03 & 0.02 & 0.02 & 0.02 & $\% \mathrm{w} / \mathrm{w}$ & & & & & EN 12916 \\
\hline $\begin{array}{l}\text { Polyaromatic } \\
\text { content }\end{array}$ & 0.50 & 0.00 & 0.45 & 0.40 & 0.35 & 0.30 & $\% \mathrm{w} / \mathrm{w}$ & & 8.0 & & & EN 12916 \\
\hline $\begin{array}{l}\text { Total aromatic } \\
\text { content }\end{array}$ & 7.92 & 0.60 & 7.19 & 6.46 & 5.72 & 4.99 & $\% \mathrm{w} / \mathrm{w}$ & & & & 1.0 & EN 12916 \\
\hline Flash point & 68.0 & $>100$ & 68.0 & 68.0 & 68.0 & 69.0 & ${ }^{\circ} \mathrm{C}$ & 55.0 & & 55.0 & & EN ISO 2719 \\
\hline $\begin{array}{l}\text { Gross calorific } \\
\text { value }\end{array}$ & 46.11 & 46.65 & 46.21 & 46.27 & 46.33 & 46.41 & $\mathrm{MJ} / \mathrm{kg}$ & & & & & ASTM D240 \\
\hline Net calorific value & 43.26 & 43.70 & 43.35 & 43.40 & 43.45 & 43.52 & $\mathrm{MJ} / \mathrm{kg}$ & & & & & ASTM D240 \\
\hline
\end{tabular}

\section{Exhaust Emissions Experimental Setup and Procedures}

3.1. Apparatus Used. The experimental work was carried out with a typical stationary diesel generator by Lister Petter. Technical specifications of the engine-generator set are provided in Table 3. No after-treatment of exhaust emissions was applied whatsoever. The engine load was manually controlled by Avtron's K490 AC resistive load bank.

Exhaust emissions (CO, $\mathrm{NO}, \mathrm{NO}_{2}$, and $\mathrm{HC}$ ) were measured with Kane 9206 Quintox gas analyzer. The sampling probe was positioned just after exhaust manifold, and the
TABle 2: Composition of HUCO used (\% w/w) [28].

\begin{tabular}{lcc}
\hline Carbon number & Normal paraffins & Isoparaffins \\
\hline C15 & 7.8 & 0.0 \\
C16 & 7.0 & 5.9 \\
C17 & 41.8 & 5.0 \\
C18 & 30.6 & 1.0 \\
\hline
\end{tabular}

exhaust gas was led to the analyzer through a heated line to avoid water condensation. Table 4 presents details about resolution, measurement range, and accuracy for the gas analyzer. 
TABLE 3: Technical specifications of engine-generator set.
Fuel injection

Number of cylinders

Aspiration

Displacement

Compression ratio

Speed

Cooling

Alternator

Electrical output power
Direct

2, inline

Natural

0.93 liters

$18.5: 1$

1500 RPM

Brushless

$5.6 \mathrm{~kW}, 50 \mathrm{~Hz}$
Liquid cooled

Particulate matter was measured in mass per exhaust gas volume units. Exhaust gas was driven through Whatman glass microfiber filters that had been thoroughly dried and weighted prior to the sampling procedure. The exhaust gas volume passing through the filter was measured with a Ritter bellowstype gas meter. To measure filter mass, a high-accuracy analytical balance with a resolution of $0.1 \mathrm{mg}$ was used.

Fuel consumption was measured by mass using a digital balance with resolution of $0.1 \mathrm{~g}$.

The experimental setup diagram is shown in Figure 2.

3.2. Experimental Procedure. The exhaust gas measurements were taken under steady-state conditions. The engine was kept running at a specific load until it reached steady-state operating conditions before any sampling took place. A k-type thermocouple was fitted in the exhaust manifold to provide exhaust gas temperature readings. This way, energy equilibrium of the engine system (indicative of steady-state operation) was identified.

After steady-state conditions had been reached, the gas analyzer started sampling. The final values at each applied load resulted from the average of ten consequent readings during a period of 10 minutes.

To measure PM, a fresh, dried, and weighted glass microfiber filter was put in a custom-made sampling probe. A custom-made buffer was positioned between the exhaust manifold and the sampling probe to help decrease gas temperature, facilitate particulate nucleosis, and ensure that too large pieces of soot, accidentally torn away from the internal walls of the sample tubing, would not get drawn onto the filter. The temperature drop is necessary to protect the filter from high temperatures, while nucleosis is needed to eliminate the existence of particulates of small diameter that would freely pass through. The PM sampling took place for different durations, depending on the engine load. This was considered necessary because at high loads, too much PM emissions accumulate on the filter, forming a thick crust that alters the filtration characteristics, while at low loads, the PM emissions are minor so that the filter net weight gets too close to the accuracy limits of the scale. After the sampling duration, the PM-loaded filter was removed, dried, and weighted again. The final PM value results from the PM net weight divided by the sampling exhaust gas volume measured by the Ritter gas meter.

After gas measurements, PM and gravimetric fuel consumption measurements were taken, the next load was
TABLe 4: Gas analyzer specifications.

\begin{tabular}{lccc}
\hline $\begin{array}{l}\text { Measured } \\
\text { variable }\end{array}$ & Resolution & $\begin{array}{c}\text { Measurement } \\
\text { range }\end{array}$ & Accuracy \\
\hline $\begin{array}{l}\text { Exhaust } \\
\text { gas temp. }\end{array}$ & $0.1^{\circ} \mathrm{C}$ & $0-1100^{\circ} \mathrm{C}$ & $1.0^{\circ} \mathrm{C} \pm 0.3 \%$ \\
\hline $\mathrm{CO}$ & $1 \mathrm{ppm}$ & $0-2000 \mathrm{ppm}$ & $\begin{array}{c} \pm 5 \% \text { when }>100 \mathrm{ppm} \text { and } \\
<2000 \mathrm{ppm} \\
\pm 10 \% \text { when }>2000 \mathrm{ppm}\end{array}$ \\
\hline $\mathrm{CO}_{2}$ & $0.1 \%$ & $0-10 \%$ & \begin{tabular}{c} 
$\pm 5 \%$ \\
\hline
\end{tabular} \\
$\mathrm{NO}$ & $1 \mathrm{ppm}$ & $0-1000 \mathrm{ppm}$ & $\begin{array}{c} \pm 5 \% \text { when }>100 \mathrm{ppm} \text { and } \\
<1000 \mathrm{ppm}\end{array}$ \\
& & & $\pm 10 \%$ when $>1000 \mathrm{ppm}$ \\
\hline $\mathrm{NO}_{2}$ & $1 \mathrm{ppm}$ & $0-100 \mathrm{ppm}$ & $\begin{array}{c} \pm 5 \mathrm{ppm} \text { when }<100 \mathrm{ppm} \\
\pm 10 \% \text { when }>100 \mathrm{ppm}\end{array}$ \\
\hline
\end{tabular}

imposed through the load bank, and the exhaust gas temperature was monitored until steady-state conditions were reached again.

The engine loads used for the measurement of exhaust emissions and fuel consumption were idle, 1.5, 3.0, 4.5, and $5.5 \mathrm{~kW}$.

\section{Results and Discussion}

4.1. Physicochemical Properties. A first assessment of HUCO as a blending component with ULSD took place regarding the physicochemical properties of the 2 fuels and the 4 blends created. HUCO measured properties were evaluated comparatively to EN 15940 standard for "class A" (high cetane number) paraffinic diesel fuels from synthesis or hydrotreatment. The properties of ULSD, H10, H20, H30, and H40 samples were evaluated comparatively to standard EN 590 for automotive diesel fuels which is currently in effect.

In general, both ULSD and HUCO fuels were found to be in compliance with their respective standards, EN 590 and EN 15940. Exceptions were the $95 \%$ v/v recovery temperature of ULSD which was slightly higher than maximum EN 590 limit and the cold filter plugging point (CFPP) of HUCO which was as expected by far exceeding the -5 degrees Celsius limit imposed for winter grade diesel fuels in the authors' region (Greece).

4.1.1. Density and Viscosity. Density noncompliance is one of the usual problems during implementation of hydrotreated oils in contemporary diesel engines because these paraffinic fuels tend to exhibit significantly lower densities than conventional petroleum diesel. This is attributed to the aliphatic nature of the compounds used for the production of such paraffinic fuels $[23,29,30]$. The density and viscosity are important properties of the fuel since they are related to the amount of injected fuel, ignition quality, fuel atomization, combustion characteristics, and volumetric fuel consumption [23, 31-34].

As shown in Figure 3, HUCO complies with EN 15940 density requirements. However, samples $\mathrm{H} 30$ and $\mathrm{H} 40$ (with 


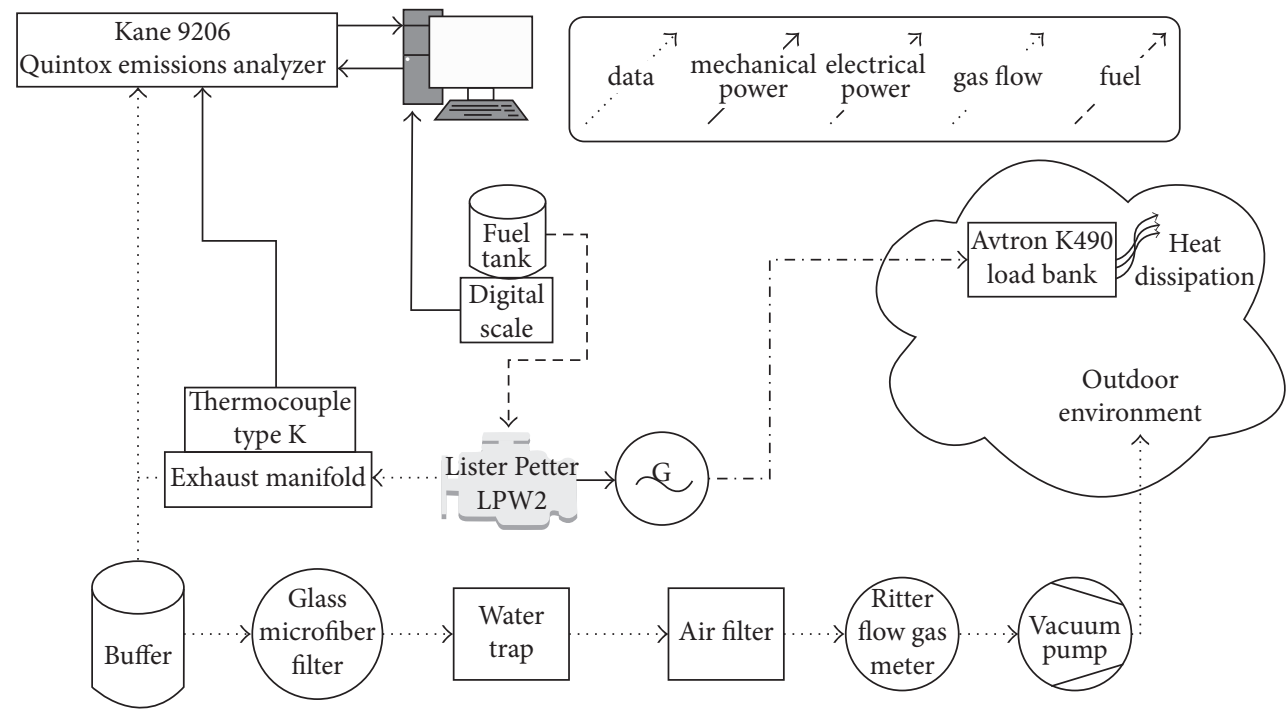

FIgURE 2: Experimental setup diagram.

$30 \%$ and $40 \% \mathrm{v} / \mathrm{v}$ concentrations of HUCO, resp.) do not meet with EN 590 lower density limit requirement.

Low density of HUCO naturally limits the volumetric concentration in which it can be mixed with typical ULSD fuels. However, if a heavier (and generally more dense) petroleum distillate were to be used as the baseline fuel, the low density of HUCO would enable higher mixing concentrations of biofuel and would allow to fully benefit from its excellent ignition quality characteristics as well $[23,30]$.

Viscosities of all fuel samples lie well within the limits, since both ULSD and HUCO meet the requirements of both standards. ULSD and HUCO viscosities were found to be very close to each other; hence, viscosities of all 4 HUCO blends were only slightly different (Figure 4). Such slight discrepancies are expected to insignificantly affect engine performance and emissions.

4.1.2. Ignition Quality. Ignition quality has been measured according to the ASTM D7170 method, which is based on a fixed-range injection period system. The apparatus consists of a constant volume combustion chamber and all necessary instrumentation to measure the duration between the start of fuel injection and start of combustion, usually referred to as Ignition Delay (ID), which is then used as a unique variable in an equation provided by the method to calculate derived cetane number (DCN).

As seen in Table 1, baseline ULSD fuel used in the present research is a high-quality petroleum product with a DCN of 60.3. Consequently, DCN was not expected to change dramatically, even with higher concentrations of HUCO, as presented in Figure 5. The reason that a highDCN baseline fuel was chosen is to make sure that this work would not be a case of "low-quality distillate upgrade." Another reason was to try and mitigate the impact of DCN on engine performance and emissions, since DCN of all

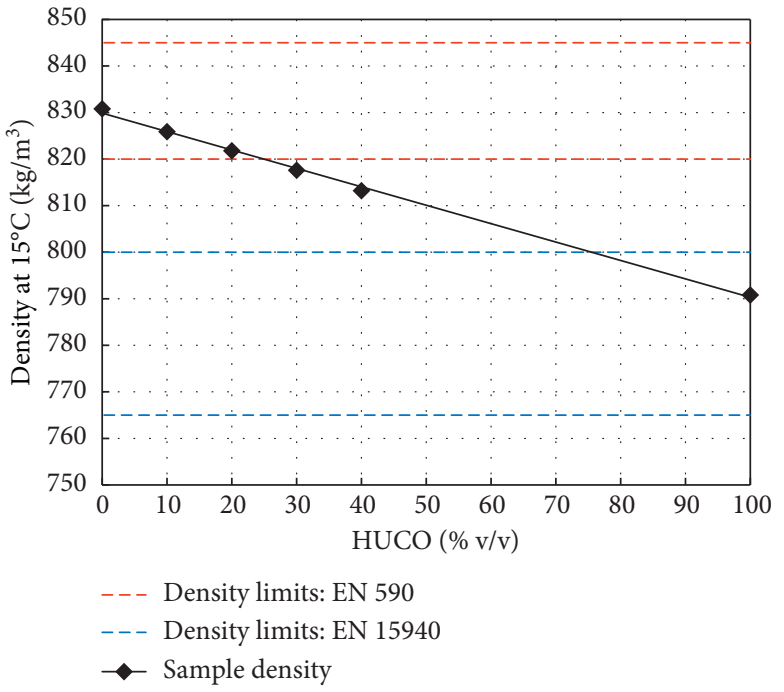

Figure 3: Density at $15^{\circ} \mathrm{C}$ of ULSD, HUCO, and their blends, measured by EN ISO 12185 standard test method.

samples evaluated are of sufficiently high values and also lie within a somewhat narrower range than if a lower DCN baseline fuel had been used.

This blending strategy creates a context where the effects of HUCO composition are being displayed a bit more clearly rather than being overshadowed by the significant impact of ignition quality characteristics.

4.1.3. Flash Point. Flash point (measured by EN ISO 2719) was found to be safely above the minimum value posed by EN 590 and EN 15940 (Table 1). More specifically, HUCO exhibits a very high flash point $\left(\right.$ over $100^{\circ} \mathrm{C}$ ) which renders itself and its blends particularly safe for transport and storage. 


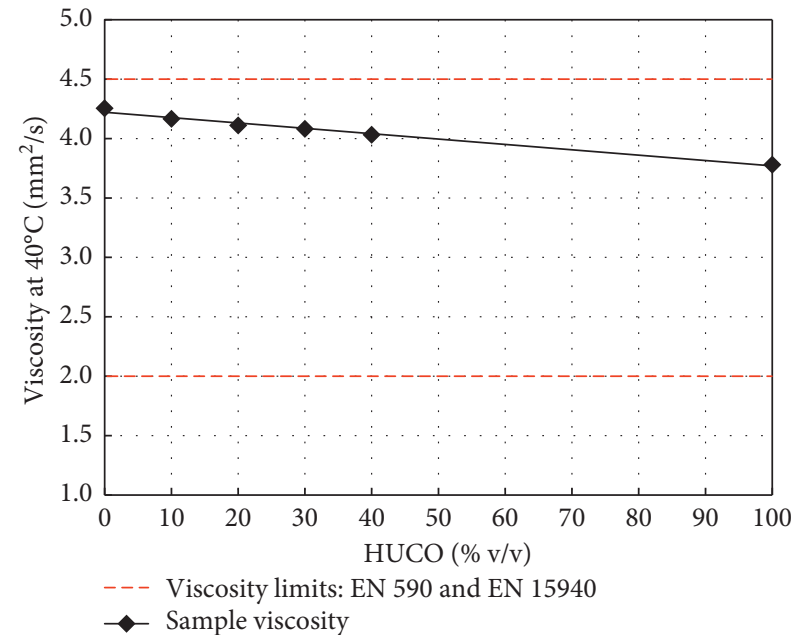

Figure 4: Viscosity at $40^{\circ} \mathrm{C}$ of ULSD, HUCO, and their blends, measured by ASTM D7042 standard test method.

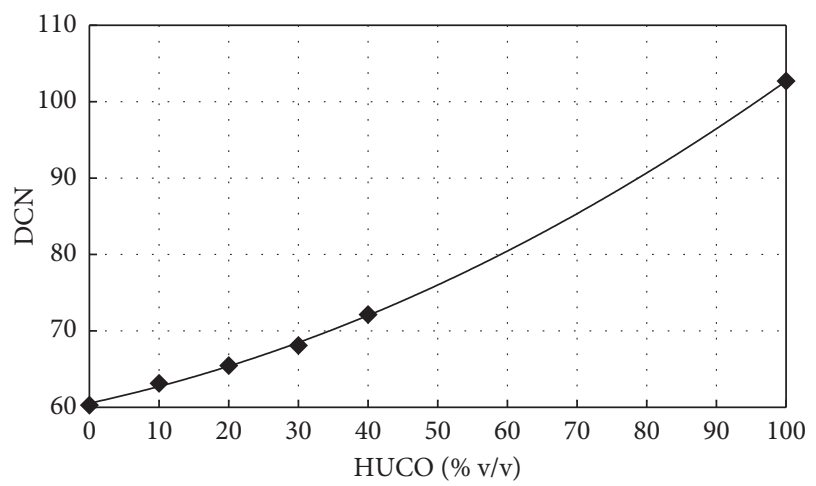

Figure 5: DCN values of ULSD, HUCO, and their blends, measured by ASTM D7170 standard test method.

4.1.4. Distillation Properties. Distillation curves of ULSD, HUCO, and their blends are presented in Figure 6. As can be seen, HUCO is a fuel consisting of very few components (see also Table 2) which results in a much narrower boiling temperature range and almost flat for the major part of the distillation curve.

As expected, HUCO addition in ULSD gradually flattens out the original curve but initial boiling point (IBP) and final boiling point (FBP) hardly change. The addition of HUCO with lower tail-end volatility ultimately helps ULSD blends to comply with the $95 \%$ vol. recovery at maximum limit of $360^{\circ} \mathrm{C}$, set by EN 590 (Table 1).

4.1.5. Cold Flow Properties. Cold flow properties were assessed by cold filter plugging point (CFPP), measured by EN 116. As Figure 7 graphically demonstrates, the negative impact of HUCO was more prominent in higher concentrations of biofuel, that is, in samples $\mathrm{H} 30$ and $\mathrm{H} 40$. Samples with lower concentrations of HUCO (H10 and H20) manage to comply with EN 590 standard's limit for winter grade $\mathrm{C}$ fuel (maximum CFPP value of $-5^{\circ} \mathrm{C}$ ). Higher proportions of HUCO can be blended in ULSD to

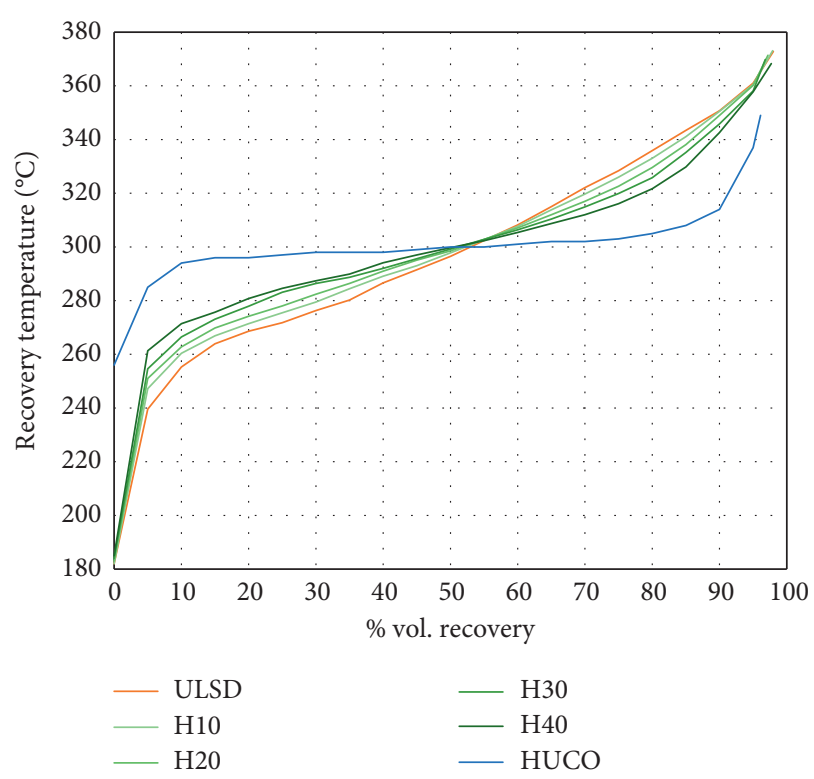

Figure 6: Distillation curves of ULSD, HUCO, and their blends, measured by EN ISO 3405 standard test method.

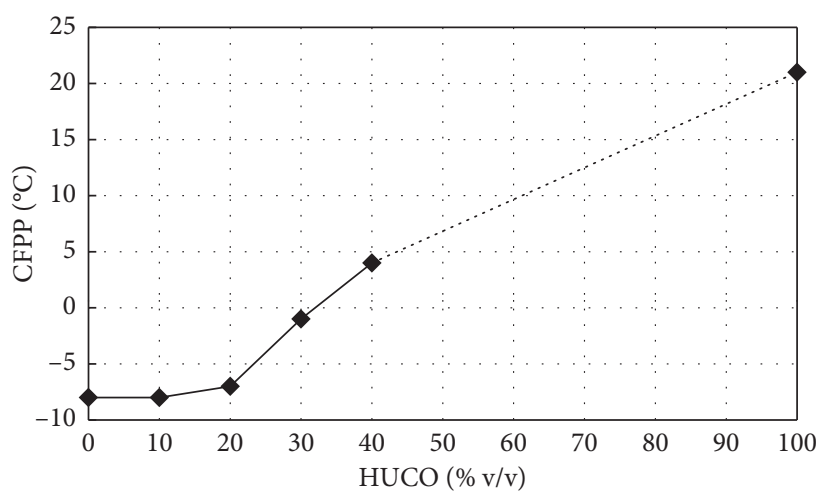

FIgURE 7: CFPP values of ULSD, HUCO, and their blends, measured by EN 116 standard test method.

create summer grade A fuel (maximum CFPP value of $+5^{\circ} \mathrm{C}$ ). For the baseline ULSD used in the present work (which has a CFPP of $-8^{\circ} \mathrm{C}$ ), it seems that HUCO concentration increasingly affects CFPP in the $20-30 \% \mathrm{v} / \mathrm{v}$ values, as indicated by the steeper slope of Figure 7. Previous research has indicated notable variances of the impact of HUCO concentration on CFPP of the blend (negative as well as beneficial impact), depending on the composition of baseline fuel [23]. This is why the blending strategy of long-chain, nonisomerized biofuels should be always planned taking into consideration the properties and composition of the baseline fuel [35-37].

4.2. Engine Results. The experimental investigation concludes with testing the baseline ULSD and the created HUCO blends on a typical stationary diesel engine. All fuels were tested at 5 engine loads corresponding to a range from idle to full load (idle, $1.5 \mathrm{~kW}, 3.0 \mathrm{~kW}, 4.5 \mathrm{~kW}$, and $5.5 \mathrm{~kW}$ ). Emissions (CO ppm, $\mathrm{HC}$ ppm, $\mathrm{NO}_{x} \mathrm{ppm}$, and $\mathrm{PM} \mu \mathrm{g} / \mathrm{L}$ ) and 
fuel consumption were measured as described in detail previously.

The engine was running smoothly at a steady speed of 1500 RPM, without obvious alteration in noise radiation during operation with ULSD and HUCO blends. This was expected as no malfunctions have been reported so far in the literature even with engines running neat paraffinic fuels $[20,33,38-42]$.

4.2.1. Fuel Consumption. Fuel consumption (FC) was measured by mass per unit of time. Figure 8 shows only a slight decrease as HUCO concentrations rise. This is naturally attributed to HUCO's higher heating value (Table 1), as also shown in previous studies on similar paraffinic fuels from hydroprocessing $[7,30,32,33,39]$.

4.2.2. Carbon Monoxide. Carbon monoxide (CO) is an indicator of incomplete combustion. Its formation occurs in regions of the cylinder with lower temperatures and/or in the absence of oxygen (e.g., higher loads where fuel/air ratio increases), when its further oxidation to $\mathrm{CO}_{2}$ formation is not favoured [43, 44].

As depicted in Figure 9, CO concentration in low-tomedium loads (up to $3 \mathrm{~kW}$ ) tends to decrease slightly as HUCO concentration in the fuel increases. In $4.5 \mathrm{~kW}$ load, only $\mathrm{H} 10$ blend exhibits a somewhat significant $\mathrm{CO}$ reduction and $\mathrm{H} 2 \mathrm{O}, \mathrm{H} 30$, and $\mathrm{H} 40$ blends perform the same as the baseline ULSD fuel. Also, in full load $(5.5 \mathrm{~kW})$, a moderate increase in $\mathrm{CO}$ concentration is observed, when the engine is running with $\mathrm{H} 30$ and $\mathrm{H} 40$ blends.

This behaviour could be indicative of lower temperatures inside the cylinder as HUCO concentration increases, therefore "freezing" the mechanism of further oxidation of $\mathrm{CO}$ to $\mathrm{CO}_{2}$. In lower loads, the slightly lower viscosity and higher DCN of HUCO blends promote spray breakup and complete combustion. This beneficial effect (observed at low-to-medium loads) could be overcome by excessive cooling phenomena (which impede oxidation of $\mathrm{CO}$ to $\mathrm{CO}_{2}$ ) and fuel/air ratio increase (which leads to incomplete combustion), during operation at higher loads when more fuel is injected inside the cylinder.

The lower in-cylinder temperatures could be a consequence of the lower aromatics and higher hydrogento-carbon (H/C) ratio of HUCO blends, since aromatic hydrocarbons (characterized by lower $\mathrm{H} / \mathrm{C}$ ratios) are known to exhibit higher adiabatic flame temperatures than paraffins [45].

4.2.3. Hydrocarbons. Hydrocarbon ( $\mathrm{HC}$ ) emissions were in all cases at very low levels, which are approaching the detection limits of the analyzer.

4.2.4. Nitrogen Oxides. Nitrogen oxides are critical pollutants produced by diesel engines. The most important mechanism for the production of $\mathrm{NO}_{x}$ is the formation of thermal NO, described by the so-called Zeldovich mechanism $[44,46]$. Nitrogen oxides are strongly dependent on

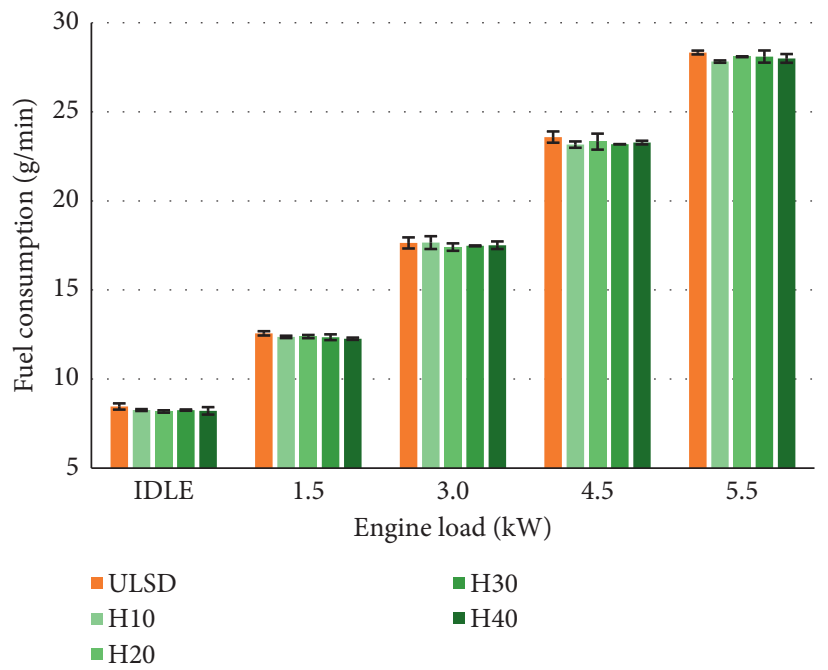

FIGURE 8: Gravimetric fuel consumption for ULSD and HUCO blends for all loads.

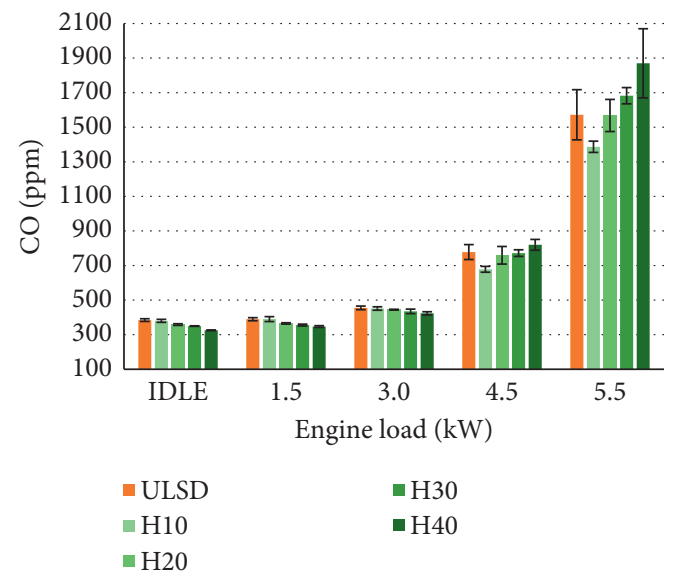

FIgURE 9: Carbon monoxide emissions for ULSD and HUCO blends for all loads.

temperature (higher temperatures promote $\mathrm{NO}_{x}$ formation) and in particular peak temperatures rather than mean combustion temperatures [44, 47].

As Figure 10 demonstrates, a slight drop in $\mathrm{NO}_{x}$ is observed in high and full loads, for higher HUCO concentrations. This effect supports the previously stated hypothesis that HUCO possibly reduces peak temperatures, simultaneously impeding $\mathrm{NO}_{x}$ formation and "freezing" the mechanism of further oxidation of $\mathrm{CO}$.

Lower aromatic content of the HUCO blends could also play a role in overall lower in-cylinder temperatures which reduce $\mathrm{NO}_{x}$ formation, according to the mechanism described above (Section 4.2.2).

In any case, the presence of HUCO in the fuel (even in concentrations as high as $40 \% \mathrm{v} / \mathrm{v}$ ) affects only slightly the overall $\mathrm{NO}_{x}$ emissions at all tested engine loads.

4.2.5. Particulate Matter. Diesel engines, praised as they may be for their thermal efficiency, robustness, and power, 


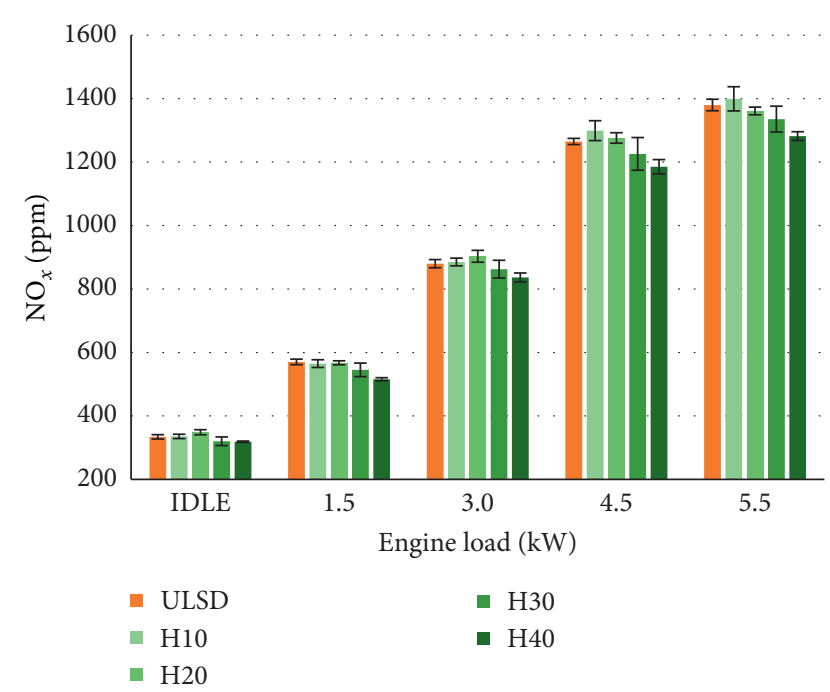

FIGURE 10: Nitrogen oxides emissions for ULSD and HUCO blends for all loads.

they are also notorious for their particulate matter (PM) emissions. In past decades, research has indicated a trade-off between nitrogen oxides and particulate matter emissions [5, 44, 47-49]. Paraffinic fuels have been studied in conjunction with engine settings fine-tuning in order to find solutions that reduce both pollutants $[20,32,33,40]$.

The present investigation indicated an overall slight decrease of PM in low-to-high loads (Figure 11). However at full load engine operation (5.5 kW), only H10 and H20 demonstrated significant PM decrease, while $\mathrm{H} 30$ seemed to cause no apparent effect and H40 affected even negatively PM emissions. As smoke in diesel engines can be indicative of incomplete combustion, the results shown in Figure 11 are in agreement with those in Figure 9 for carbon monoxide. Furthermore, higher PM emissions at full load and higher HUCO concentrations (H30 and H40) are in accordance with the simultaneous $\mathrm{NO}_{x}$ decreasing trend (Figure 10). As also hypothesized by previous research with similar findings [45], PM increase can be attributed to the higher DCN of HUCO which can promote a growth of the diffusive combustion, leading to mitigation of the beneficial effects of such an aromatic-free blending component.

\section{Conclusions}

This study focuses on the possibility to utilize paraffinic fuels from liquid biomass hydroprocessing in standard diesel engines as blending components with typical ULSD fuel. The omission of the isomerization step can further promote the use of such 2 nd generation biofuels by reducing their production costs.

Nonisomerized HUCO physicochemical properties were found to meet with EN 15940 standard for "high cetane" paraffinic fuels from hydrotreatment, except its CFPP value which was as expected very high.

However, strategic mixing of HUCO with ULSD can produce usable fuel blends complying with EN 590 standard.

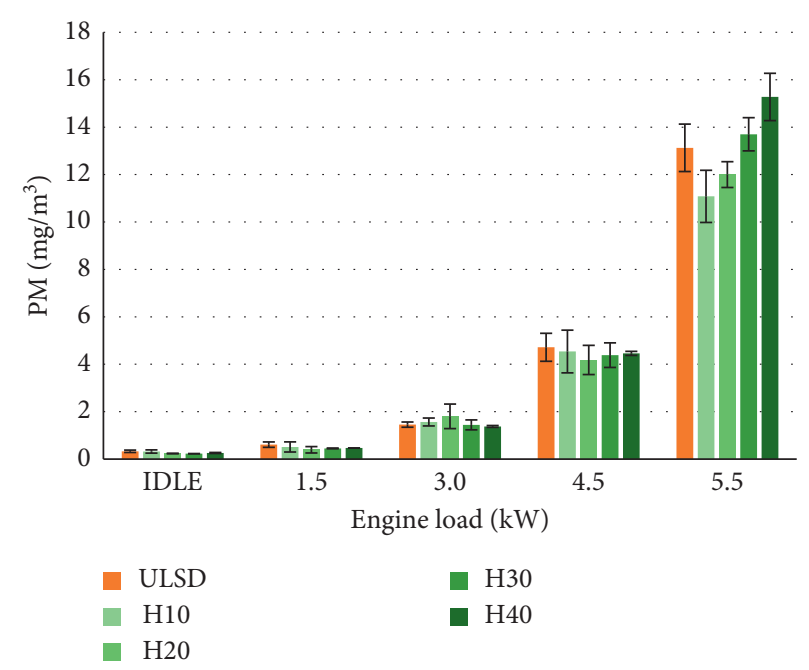

FIgUre 11: Particulate matter emissions for ULSD and HUCO blends for all loads.

More specifically, it was found that up to $20 \% \mathrm{v} / \mathrm{v}$ HUCO in ULSD can create a fully compliant "winter grade" fuel according to EN 590 (for temperate climates). Higher HUCO (up to $40 \% \mathrm{v} / \mathrm{v}$ ) concentrations can be used to create "summer grade" fuels, however in order to meet with density requirements of EN 590, heavier distillate base fuels must be considered. When concentration of HUCO in ULSD remains within conservative/practical limits (up to $10-15 \%$ $\mathrm{v} / \mathrm{v}$ ), the physicochemical properties of the blend are almost identical to those of the neat petroleum diesel fuel.

Moreover, nonisomerized HUCO can be used to greatly improve ignition quality, lower sulfur, and aromatic content of the blend and slightly increase the heating value, all depending on the base diesel fuel used.

Engine tests were conducted without any modification of operating parameters, such as injection timing. The reason for that is to evaluate the HUCO blends as drop-in replacements for standard, non-highly sophisticated diesel engines.

During engine tests, a slight decreasing trend at all loads was found concerning $\mathrm{NO}_{x}$ emissions as HUCO concentration increased. This can be attributed to overall lower temperatures inside the cylinder resulting from lower aromatic content and higher $\mathrm{H} / \mathrm{C}$ ratio of HUCO blends.

Carbon monoxide (CO) and particulate matter (PM) show a minimal decrease at low-to-medium loads but moderately increase in high and full loads during operation with higher HUCO concentration blends (30\% and $40 \%$ $\mathrm{v} / \mathrm{v})$. This probably has to do with lower in-cylinder temperatures promoted by HUCO composition and overly high derived cetane number (DCN) of $30 \%$ and $40 \%$ v/v HUCO blends.

Gravimetric fuel consumption was as expected decreasing as HUCO concentration increases, due to higher HUCO heating value.

All in all, nonisomerized HUCO fuel can be incorporated even in high volumetric concentrations through strategic mixing with typical ULSD fuels without dramatically affecting engine operation, fuel consumption, and 
exhaust emissions. However, to maximize the usage benefits of such a high-quality biofuel, engine fine-tuning may be considered and further investigated.

\section{Data Availability}

The data used to support the findings of this study are available from the corresponding author upon request.

\section{Conflicts of Interest}

The authors declare that they have no conflicts of interest.

\section{References}

[1] ACEA Statistics, "European Automobile Manufacturers Association," February 2018, http://www.acea.be/.

[2] United States Environmental Protection Agency, "Global greenhouse gas emissions data," February 2018, https://www. epa.gov/ghgemissions/global-greenhouse-gas-emissions-data/.

[3] European Environment Agency, "Greenhouse gas emissions from transport," February 2018, https://www.eea.europa.eu/ data-and-maps/indicators/transport-emissions-of-greenhousegases/transport-emissions-of-greenhouse-gases-10/.

[4] P. Duffy, "On the constitution of stearine," Quarterly Journal of the Chemical Society of London, vol. 5, no. 4, pp. 303-316, 1853.

[5] G. Knothe, J. Krahl, and J. Gerpen, The Biodiesel Handbook, Academic Press and AOCS Press, Oxford, UK, 2nd edition, 2010.

[6] L. C. Meher, S. D. Vidya, and S. N. Naik, "Technical aspects of biodiesel production by transesterification-a review," Renewable and Sustainable Energy Reviews, vol. 10, no. 3, pp. 248-268, 2006.

[7] S. Bezergianni, "Catalytic hydroprocessing of liquid biomass for biofuels production," in Liquid, Gaseous and Solid Biofuels-Conversion Techniques, pp. 299-326, INTECH, London, UK, 2013, ISBN 978-953-51-1050-7.

[8] S. N. Naik, V. V. Goud, O. J. Rout, and A. K. Dalai, "Production of first and second generation biofuels: a comprehensive review," Renewable and sustainable Energy Reviews, vol. 14, no. 2, pp. 578-597, 2010.

[9] X. Zhang, C. Peterson, D. Reece, R. Haws, and G. Möller, "Biodegradability of biodiesel in the aquatic environment," Transactions of the ASAE, vol. 41, no. 5, pp. 1423-1430, 1998.

[10] J. C. Pasqualino, D. Montané, and J. Salvadó, "Synergic effects of biodiesel in the biodegradability of fossil- derived fuels," Biomass and Bioenergy, vol. 30, no. 10, pp. 874-879, 2006.

[11] G. Knothe, "Some aspects of biodiesel oxidative stability," Fuel Processing Technology, vol. 88, no. 7, pp. 669-677, 2007.

[12] G. Karavalakis, S. Stournas, and D. Karonis, "Evaluation of the oxidation stability of diesel/biodiesel blends," Fuel, vol. 89, no. 9, pp. 2483-2489, 2010.

[13] G. R. Timilsina and A. Shrestha, "How much hope should we have for biofuels?,” Energy, vol. 36, no. 4, pp. 2055-2069, 2011.

[14] M. Stumborg, A. Wong, and E. Hogan, "Hydroprocessed vegetable oils for diesel fuel improvement," Bioresource Technology, vol. 56, no. 1, pp. 13-18, 1996.

[15] J. H. Gary and G. E. Handwerk, Petroleum Refining Technology and Economics, Marcel Dekker, New York, NY, USA, 4th edition, 2001.

[16] P. Baladincz and J. Hancsók, "Fuel from waste animal fats," Chemical Engineering Journal, vol. 282, pp. 152-160, 2015.
[17] D. Chiaramonti, M. Buffi, A. M. Rizzo, M. Prussi, and F. Martelli, "Bio-hydrocarbons through catalytic pyrolysis of used cooking oils: towards sustainable jet and road fuels," Energy Procedia, vol. 82, pp. 343-349, 2015.

[18] E. A. Salwa, H. A. Samia, M. M. H. Arief Eslam, and F. Al-Amrousi, "Production of petroleum-like fractions from waste cooking oil," Egyptian Journal of Chemistry, vol. 60, no. 1, pp. 147-160, 2017.

[19] P. Solymosi, G. Varga, and J. Hancsók, "Investigation of quality improving of waste origin bio-paraffins," Chemical Engineering Transactions, vol. 39, pp. 1387-1392, 2014.

[20] N. O. Nylund, K. Erkkilä, M. Ahtiainen et al., Optimized Usage of NExBTL Renewable Diesel Fuel, OPTIBIO, Ville-d'Avray, France, 2014.

[21] T. Tyrovola, G. Dodos, S. Kalligeros, and F. Zannikos, "The introduction of biofuels in marine sector," Journal of Environmental Science and Engineering A, vol. 6, no. 8, pp. 415-421, 2017.

[22] G. W. Huber, P. O'Connor, and A. Corma, "Processing biomass in conventional oil refineries: production of high quality diesel by hydrotreating vegetable oils in heavy vacuum oil mixtures," Applied Catalysis A: General, vol. 329, pp. 120-129, 2007.

[23] D. Karonis, D. Chilari, and C. Manou, "Characterization of hydroprocessed used cooking oils in blend with low quality gasoil samples," SAE International Journal of Fuels and Lubricants, vol. 7, no. 1, 2014.

[24] B. S. Glisic, M. J. Pajnik, and M. A. Orlovic, "Process and techno-economic analysis of green diesel production from waste vegetable oil and the comparison with ester type biodiesel production," Applied Energy, vol. 170, pp. 176-185, 2016.

[25] H. De Paz Carmona, J. Horáček, A. B. Alayón, and J. J. Macías Hernández, "Suitability of used frying oil for co-processing with atmospheric gas oil," Fuel, vol. 214, pp. 165-173, 2018.

[26] J. Mikulec, J. Cvengroš, L. Joríková, M. Banič, and A. Kleinová, "Second generation diesel fuel from renewable sources," Journal of Cleaner Production, vol. 18, no. 9, pp. 917-926, 2010.

[27] BIOFUELS-2G, "2nd Generation Biofuels for Urban Environment," February 2018, http://www.biofuels2g.gr/.

[28] S. Bezergianni, A. Dimitriadis, T. Sfetsas, and A. Kalogianni, "Hydrotreating of waste cooking oil for biodiesel production. Part II: effect of temperature on hydrocarbon composition," Bioresource Technology, vol. 101, no. 19, pp. 7658-7660, 2010.

[29] G. Knothe, "Biodiesel and renewable diesel: a comparison," Progress in Energy and Combustion Science, vol. 36, no. 3, pp. 364-373, 2010.

[30] M. Lapuerta, M. Villajos, J. R. Agudelo, and A. L. Boehman, "Key properties and blending strategies of hydrotreated vegetable oil as biofuel for diesel engines," Fuel Processing Technology, vol. 92, no. 12, pp. 2406-2411, 2011.

[31] I. Barabás and I. Todoru, "Utilization of biodiesel-dieselethanol blends in CI engine," in Biodiesel-Qual. Emiss. ByProducts, G. Montero, Ed., InTech, London, UK, 2011.

[32] F. Millo, B. K. Debnath, T. Vlachos, C. Ciaravino, L. Postrioti, and G. Buitoni, "Effects of different biofuels blends on performance and emissions of an automotive diesel engine," Fuel, vol. 159, pp. 614-627, 2015.

[33] H. Aatola, M. Larmi, T. Sarjovaara, and S. Mikkonen, "Hydrotreated vegetable oil (HVO) as a renewable diesel fuel: trade-off between $\mathrm{NO}_{x}$, particulate emission, and fuel consumption of a heavy duty engine," SAE International Journal of Engines, vol. 1, no. 1, pp. 1251-1262, 2009. 
[34] X. Wang, Z. Huang, O. A. Kuti, W. Zhang, and K. Nishida, "Experimental and analytical study on biodiesel and diesel spray characteristics under ultra-high injection pressure," International Journal of Heat and Fluid Flow, vol. 31, no. 4, pp. 659-666, 2010.

[35] F. I. C. Mirante and J. A.P. Coutinho, "Cloud point prediction of fuels and fuel blends," Fluid Phase Equilibria, vol. 180, no. 1-2, pp. 247-255, 2001.

[36] P. B. Semwala and R. G. Varshney, "Predictions of pour, cloud and cold filter plugging point for future diesel fuels with application to diesel blending models," Fuel, vol. 74, no. 3, pp. 437-444, 1995.

[37] C. Wu, J. Zhang, W. Li, Y. Wang, and H. Cao, "Artificial neural network model to predict cold filter plugging point of blended diesel fuels," Fuel Processing Technology, vol. 87, no. 7, pp. 585-590, 2006.

[38] A. D. Bugarski, J. A. Hummer, and S. Vanderslice, "Effects of hydrotreated vegetable oil on emissions of aerosols and gases from light-duty and medium-duty older technology engines," Journal of Occupational and Environmental Hygiene, vol. 13, no. 4, pp. 293-302, 2016.

[39] D. Singh, K. A. Subramanian, and S. K. Singal, "Emissions and fuel consumption characteristics of a heavy duty diesel engine fueled with hydroprocessed renewable diesel and biodiesel," Applied Energy, vol. 155, pp. 440-446, 2015.

[40] D. Singh, K. A. Subramanian, and M. O. Garg, "Comprehensive review of combustion, performance and emissions characteristics of a compression ignition engine fueled with hydroprocessed renewable diesel," Renewable and Sustainable Energy Reviews, vol. 81, pp. 2947-2954, 2018.

[41] M. Kousoulidou, A. Dimaratos, A. Karvountzis-Kontakiotis, and Z. Samaras, "Combustion and emissions of a commonrail diesel engine fueled with HWCO," Journal of Energy Engineering, vol. 140, no. 3, p. A4013001, 2014.

[42] A. Singer, O. Schröder, C. Pabst et al., "Aging studies of biodiesel and HVO and their testing as neat fuel and blends for exhaust emissions in heavy-duty engines and passenger cars," Fuel, vol. 153, pp. 595-603, 2015.

[43] C. K. Law, Combustion Physics, Cambridge University Press, Cambridge, UK, 2006, ISBN 978-0-521-87052-8.

[44] K. Mollenhauer and H. Tschoeke, Handbook of Diesel Engines, Springer Berlin Heidelberg, Berlin, Germany, 2010.

[45] G. Karavalakis, Y. Jiang, J. Yang, T. Durbin, J. Nuottimäki, and K. Lehto, "Emissions and fuel economy evaluation from two current technology heavy-duty trucks operated on HVO and FAME blends," SAE International Journal of Fuels and Lubricants, vol. 9, no. 1, pp. 177-190, 2016.

[46] Y. B. Zeldovich, P. Y. Sadovnikov, and D. A. FrankKamenetskii, Oxidation of Nitrogen in Combustion, Moscow-Leningrad: Academy of Sciences of USSR, Institute of Chemical Physics, Moscow, Russia, 1947.

[47] C. D. Rakopoulos and E. G. Giakoumis, Diesel Engine Transient Operation-Principles of Operation and Simulation Analysis, Springer, London, UK, 2009.

[48] R. L. McCormick, A. Williams, J. Ireland, M. Brimhall, and R. R. Hayes, "Effects of biodiesel blends on vehicle emissions," NREL report, National Renewable Energy Laboratory, Lakewood, CO, USA, 2006.

[49] A. Fayyazbakhsh and V. Pirouzfar, "Comprehensive overview on diesel additives to reduce emissions, enhance fuel properties and improve engine performance," Renewable and Sustainable Energy Reviews, vol. 74, pp. 891-901, 2017. 


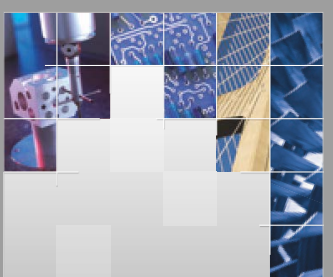

\section{Enfincering}
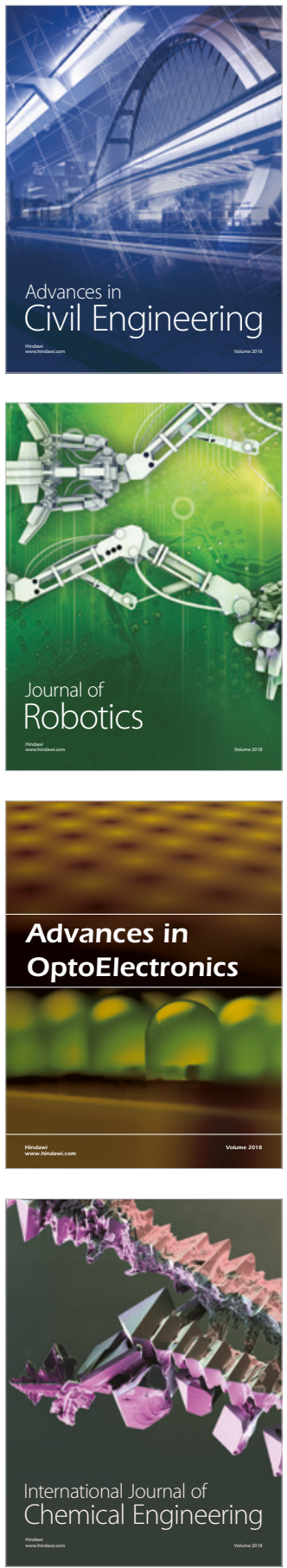

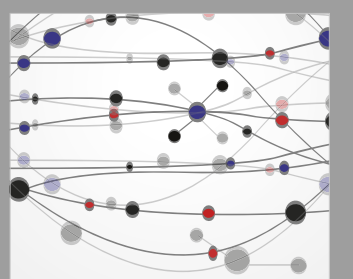

\section{Rotating \\ Machinery}

The Scientific World Journal

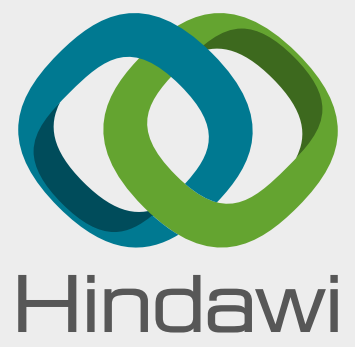

Submit your manuscripts at

www.hindawi.com
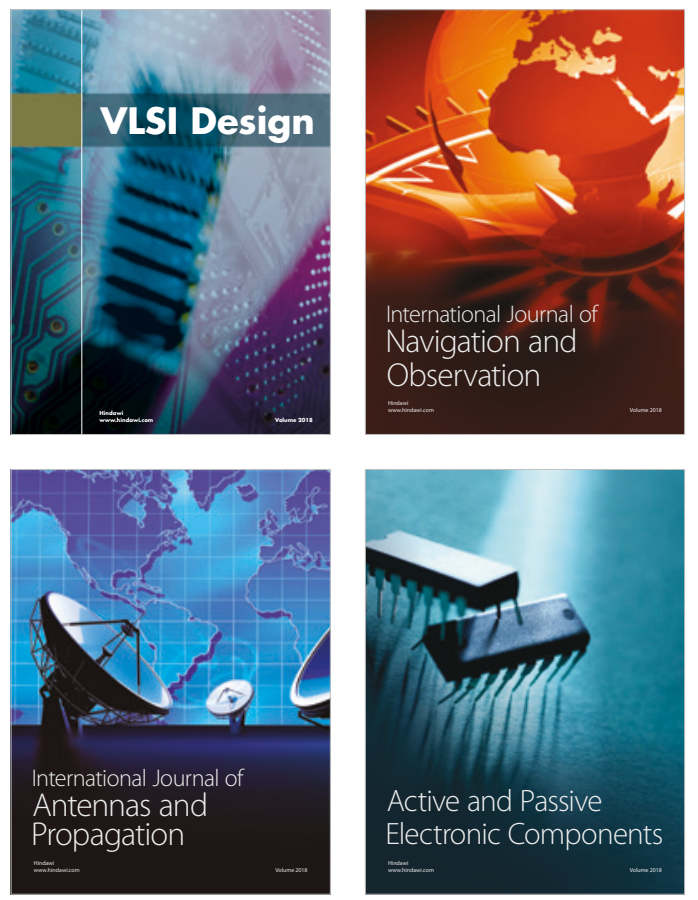
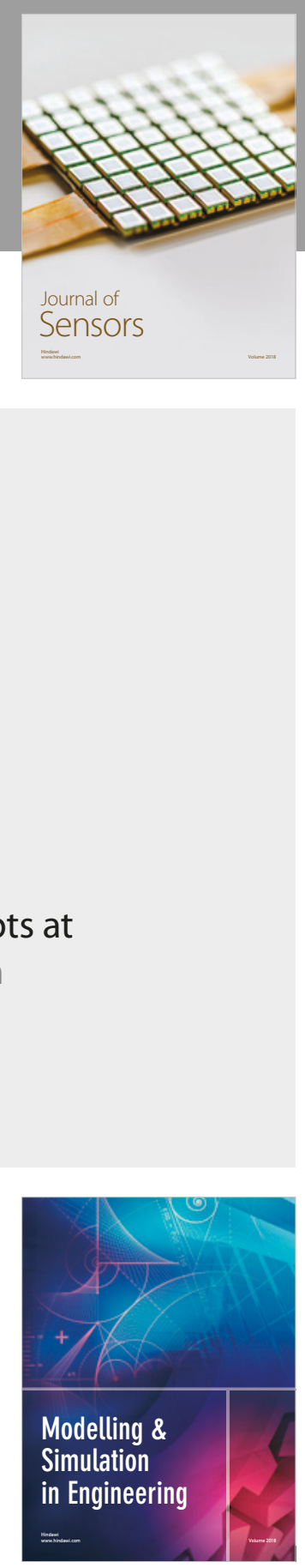

\section{Advances \\ Multimedia}
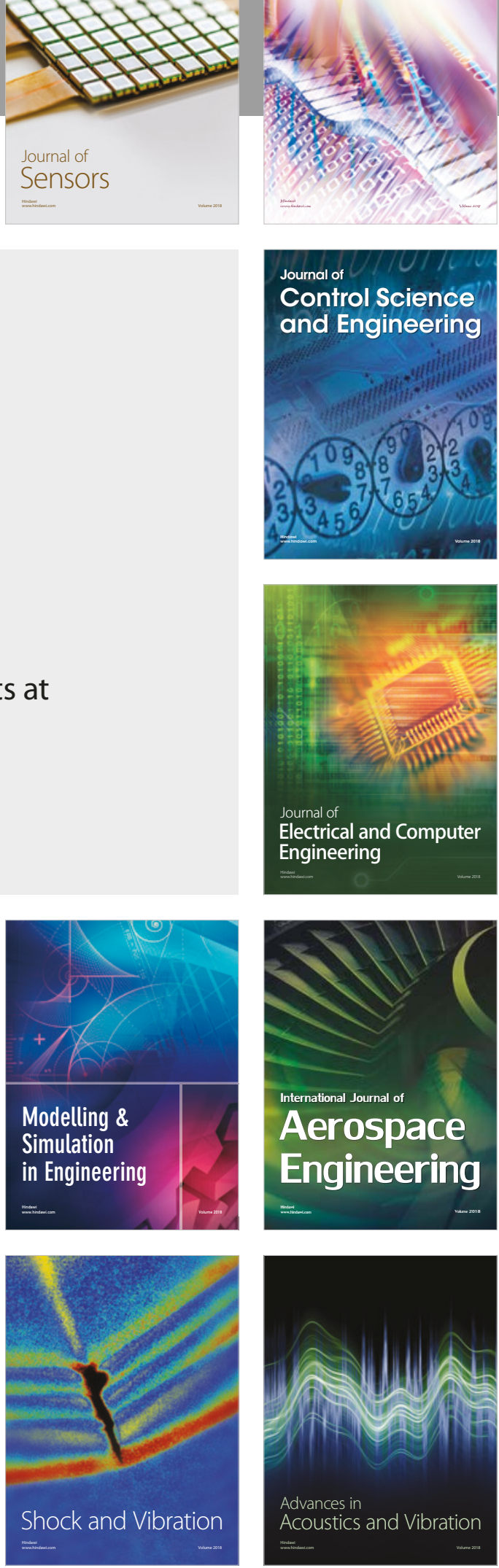